\title{
The Impact of organizational Learning Culture's on Job Satisfaction, Organizational Commitment, and Turnover Intention among Privet sector in Saudi Arabia
}

\author{
Abdelmohsen A. Nassani ${ }^{1 *} \quad$ Faris Khaled Altuwaijri ${ }^{1 * *}$ \\ 1. Department of Management, College of Business Administration, King Saud University, P.O. Box \\ 71115, Riyadh 11587, Saudi Arabia. \\ *nassani@ksu.edu.sa **farisaltuwaijri@gmail.com
}

\begin{abstract}
Organizational learning culture has positive impact with job satisfaction on the productivity of the organization, this study showed that there is a negative relationship between the organizational learning culture and turnover intention which the employees in the organizations they are not linked ;earning with their intention to leave, we figure out in this study the job satisfaction positively influence organizational commitment this is refer for the employees will have the commitment for their organizations when they have job satisfaction first and organizational commitment has negative relationship with turnover intention, the studies shown that there are employees that could stay in the organization even of they do not have commitment for their organizations.
\end{abstract}

Keywords: Organizational learning culture, job satisfaction, organizational commitment, turnover intention, privet sector and Saudi Arabia

DOI: $10.7176 / \mathrm{EJBM} / 13-8-17$

Publication date: April $30^{\text {th }} 2021$

\section{Introduction}

In the last decade, organizational learning has been one of the most widely used and fastest-growing interventions in HRD practice to improve organizational effectiveness (Cummings \& Worley, 2005). As a result, a slew of studies has investigated the theoretical and operational models of an organizational learning culture, as well as their contribution to employee success such as employee satisfaction, organizational commitment, and the likelihood of turnover. Other research has linked improved organizational efficiency (Kontoghiorghes, Awbery, \& Feurig, 2005; Kuchinke, 1995; Kontoghiorghes, Awbery, \& Feurig, 2005; Kontoghiorghe, et al 2007; Lien, Huang, et al 2002). A review of the research on the connection between learning organizations and success.

Personal know-how and implicit information, according to Drucker (1999a), are not retained inside an organization; rather, workers retain this knowledge. organizations practitioners have intellectual resources and information capital as reserves. When organizations professionals leave a company and take their assets with them, it may cause a construction project to halt and a loss of tacit information that cannot be quickly replaced with new hires. Furthermore, according to Kochanski and Ledford (2001), the expense of losing organizations practitioners is three to six times that of losing an administrative employee.

Employees' decision to leave the company is one of the most important factors affecting the company's success because it influences overall profitability. Organizations must strategize to minimize employee turnover to gain a competitive edge over their competitors. By gaining a better understanding of the factors that influence an employee's decision to leave, you will prevent them from leaving (Lin Chun yu, et al 2021).

A conscious and expected willingness to depart an organization is referred to as turnover intention. The worker's turnover intention serves as a mental precursor to their final turnover behavior before leaving the company. High intentional turnover has a detrimental impact on the growth and development of a company. It results in a staffing shortage and an undue burden on current employees, resulting in burnout. satisfaction and organizational development which one of their factors are the salary scale of the organization but they have a lot of other things not related to it. And for many other dimensions that effected by turnover intention (Przemyslaw, 2019).

Previous research has found a connection between workplace bullying and the intention to leave 10. However, in our society, there is an awareness gap about the incidence of workplace bullying, as many instances go unreported due to cultural barriers. 11th. Managers cannot develop solutions or concentrate on an issue unless they are aware 
of its presence and its ramifications (Fourth International Conference, 2020).

It has been demonstrated that it not only promotes cooperation in corona countermeasures but also increases turnover intention. This means that, while raising employee anxiety will achieve the short-term goal of getting them to comply with the company's corona countermeasures, it may not achieve the longer-term goal of increasing their intention to quit (Mishal Liaqat1, et al 2021).

The effects of workplace ostracism on turnover intention were partly mediated by openness to practice and neuroticism, with resilience moderating the mediating effects. The findings will aid in the investigation of the role of resilience in altering the process linking workplace ostracism and intention to leave. The analysis is the first of its kind in India, and it includes variables such as workplace ostracism, to better understand their effect on the hotel industry, researchers looked at turnover intention and personality variables. The research has introduced a new dimension to the prevalent frame of understanding by linking it to the viewpoint of resource conservation (Kokubun, 2020), The direct, mediating, and moderating effects were evaluated using structural equation modeling. The findings revealed that organizational commitment and work satisfaction completely mediated the relationship between work and the intention to leave. (Mishal Liaqat1, et al 2021).

Based on the previse, the research will study how the organizational learning culture will affect job satisfaction and turnover intention and on the other side how job satisfaction will directly affect organizational development, and this study came to participating in solving a common problem in Saudi Arabia which is the turnover intention, a lot of company they are losing their resources because of this problem which we will help to figure out the reasons.

\section{Literature Review}

2.1 Theoretical Background and Hypothesis Development

2.1.1 The relationship between organizational learning culture and job satisfaction

OLC has emerged as the preeminent training method for providing easy access to knowledge and a customized training experience, resulting in increased efficiency, productivity, and retention (Batalla- Busquets \& PachecoBernal, 2013; Brown \& Charlier, 2013; Navimipour, Rahmani, Navin, \& Hosseinzadeh, 2015; Yoo et al., 2015), Individual employee technology acceptance levels for e-learning systems and their effect on job satisfaction were examined by Yoo and Huang (2016) in the context of organizational learning, Exploring employee acceptance levels for e-learning programs, according to their results, will help cultivate an OLC.

Job satisfaction can be a key predictor of employee job attitudes that have been affected by an OLC or a knowledgesharing culture when considering the optimization of human resources and the retention of talent (Belias \& Koustelios, 2014, wong 2015, There have been no longitudinal research on the relationship between employee adoption of e-learning, expectations of an OLC, and work satisfaction. As a result, this analysis aimed to close the research gap by looking at the relationships between these three variables.

The research of Yoo and Huang (2016) helps to ensure that using e-learning systems can speed up the creation process, Egan et al. (2004) conducted a survey of IT industry workers in the United States and found that an OLC is a valid construct in predicting employee job satisfaction, HR professionals can improve employee psychological empowerment and work satisfaction while lowering attrition by strengthening an existing OLC (Chang \& Lee., 2007; Islam et al., 2014; Joo \& Park, 2010), When addressing the interaction between employee work satisfaction and the four underlying dimensions of e-learning system acceptance levels.

the current OLC must be considered. Understanding how the related variables of e-learning systems, OLC, and work satisfaction interact, is critical to provide HR researchers and practitioners with insights into how to build a workplace atmosphere that promotes effective learning and advancement in each profession, based on the previous studies we could formulate the below hypothesis:

H1: The OLC is positively associated with employee job satisfaction. 


\subsubsection{The relationship between organizational learning culture and Turnover intention}

Although organizational learning is among the most widespread and fastest-growing interventions in HRD practice (Cummings \& Worley, 2005), the context of organizational learning culture related to its interaction with turnover intention has not been explored extensively (Egan et al., 2004; Lee-Kelley et al., 2007), In the context of social exchange theory, employees who receive sufficient and relevant training opportunities in organizations might be more reluctant to leave their organization (Shore, Tetrick, Lynch, \& Barksdale, 2006)

Thus, if employees perceive that they have more training opportunities, then it may result in diminishing their turnover intention (Chow, Haddad, \& Singh, 2007; Dysvik \& Kuvaas, 2008; Hemdi \& Nasurdin, 2006; Pfeffer \& Sutton, 2006). Similarly, Lankau and Scandura (2002) reported that job learning is negatively associated with turnover intention. Karatepe, Yavas, and Babakus (2007) suggested that job resources, including supervisory support, training, empowerment, and rewards, increase employees' job satisfaction and affective commitment and reduce their turnover intention. Pare and Tremblay (2007) indicated that competence development and information sharing have a negative effect on turnover intention. While there is limited empirical evidence to support a relationship between organizational learning culture and turnover intention, the research that has been done supports this connection.

Based on Gouillart and Kelly (1995), and organizational culture that encourages employees' self-development may reduce individuals' desire to seek employment elsewhere if they are acquiring new skills and competencies that allow them to increase their self-efficacy.

Egan et al. (2004). demonstrated that a learning culture impacted job satisfaction; in addition, a learning culture was mediated by job satisfaction, with a negative effect on turnover intention. Lee-Kelley et al. (2007) conducted a study exploring learning organizations and the retention of knowledge workers in the private industry.

The researchers applied Senge's five learning organization disciplines to explore the relationship between job satisfaction and turnover intention. They concluded that shared vision, which is one of the learning disciplines, has a negative relationship to turnover intention because knowledge workers were strongly influenced by a shared vision and showed decreased turnover intention, based on the previous studies we could formulate the below hypothesis:

\section{H2: Organizational learning culture negatively influences turnover intention.}

\subsubsection{The relationship between job satisfaction and organizational commitment}

Organizational commitment and job satisfaction are considered distinct constructs. Job satisfaction is an emotional state that reflects an effective response to one's job and work environment (Gregson, 1987; Lock, 1976; Porter et al., 1974), Organizational commitment, on the other hand, puts a greater focus on a global response (emotional or non-emotional) to the whole organization (Lance, 1991; Porter et al., 1974). As a result, everyday events have less of an effect on organizational loyalty, and it develops more consistency over time than work satisfaction (Mowday, Steers, \& Porter, 1979; Sagie, 1998).

Even though there is a general agreement that there is a clear positive relationship between work satisfaction and organizational commitment, there is a debate about the causal order of these two variables. Strasser and Bateman (1984), argued that organizational loyalty is a predictor of job satisfaction, implying that when workers have a deep commitment to their company, their job satisfaction will increase. Job satisfaction has been linked to organizational commitment in many other studies (Bluedorn, 1982a; Williams \& Hazer, 1986), A third viewpoint regards the relationship as mutual (Mathieu \& Zajac, 1990; Meyer, Staneley, Herscovitch, \& Topolnytsky, 2002).

Much research tends to show that job satisfaction is affected by a variety of other factors that have a positive effect on organizational commitment. Training and education (Griffeth et al., 2000; Yu \& Egri, 2005), and ethical climate (Cullen, Parboteeah, \& Victor, 2002; Schwepker, 2001), a supportive and innovative culture (Lok \& Crawford, 2001), role stressors (Griffeth et al., 2000; Yu \& Egri, 2005), and role stressors (Griffeth et al., 2000; Yu \& Egri, 2005 (Igbaria \& Guimaraes, 1993; Johnston, Parasuraman, Futrell, \& Black, 1990), and professional growth (Igbaria \& Greenhaus, 1992). As result, this study takes this stance because the employees enjoy autonomy and versatility, and when they are happy in their employment, they are more likely to identify with and participate in 
their organizations (Goswami et al., 2007), As a result, they are more likely to have "a firm belief in and appreciation of the organization's goals and principles" (Mowday et al., 1979, p. 226).

Overall success in an academic institute is determined by a teacher's actions and attitudes, which should be nurtured in such a way that the teacher's job satisfaction and dedication are increased (Bashir and Gani, 2019). Positive job satisfaction, according to Grace and Khalsa (2003), will improve a teacher's organizational commitment, Employees who work in a positive university setting are more likely to be satisfied with their jobs (Anari, 2012), which increases organizational commitment and increases university productivity (Sabri et al., 2011; Malik et al., 2010), Based on the previous studies we could formulate the below hypothesis:

H3: Job satisfaction positively influences organizational commitment.

\subsubsection{The relationship between organizational commitment and turnover intention}

According to Barak et al., work satisfaction, organizational commitment, technical commitment, and burnout are the best predictors of turnover intention (2001). Indeed, several research on the motivation to leave has found that work satisfaction and organizational commitment are both important factors (Carayon, Schoepke, Hoonakker, Haims, \& Brunette, 2006).

Many studies of organizational commitment and turnover intention have been conducted in the past. Mathieu and Zajac (1990) accepted Nowadays et al.'s (1982)'s prediction that organizational commitment has a negative relationship with turnover intention in a meta-analysis of 200 commitment studies, their research also found that employees who are dedicated to their employers are more likely to stay with them. Similarly, Tett and Meyer (1993) discovered that organizational commitment was a predictor of turnover intention in a meta-analysis of 155 studies with 178 independent samples. Using a longitudinal design, Johnston et al. (1990) supported these results.

As previously mentioned, organizational commitment is made up of three elements: affective, continuous, and normative (Meyer \& Allen, 1991). While the majority of studies on affective commitment have found that the strongest and most stable relationship with turnover intention is with affective commitment (Iverson \& Buttigieg, 1999; Meyer \& Allen, 1997; Vandenberghe \& Tremblay, 2008; Wasti, 2003).

researchers have found a significantly negative relationship between continuance commitment and turnover intention (e.g., Chen, Hui, \& Sego, 1998; Jaros, Jermier, Koehler, \& Sincich, 1993; Meyer et al., 2002; Udo, Guimaraes, \& Igbaria, 1997), Pare and Tremblay (2007).

investigated the effect of continuity commitment on turnover intention and discovered that employees are likely to remain with their company not only because of emotional connection, but also because of financial incentives, but also because of the expense of quitting. As a result, it has been discovered that continuance commitments processed as a perceived expense correlate more strongly than affective and normative commitments (Dunham, Grube, \& Castaneda, 1994; Meyer, Allen, \& Gellatly, 1990; Wasti, 2003), These findings are supported by research findings in the literature for organizations professionals (Chang \& Choi, 2007; Iverson, Mueller, \& Price, 2004), Based on the previous studies we could formulate the below hypothesis:

H4: Organizational commitment negatively influences turnover intention. 


\subsection{Research Model}

Figure 1 illustrates how organizational learning culture impacts job satisfaction, organizational commitment, and turnover intention and how all these variables affect the turnover intentions in the organizations in Saudi Arabia.

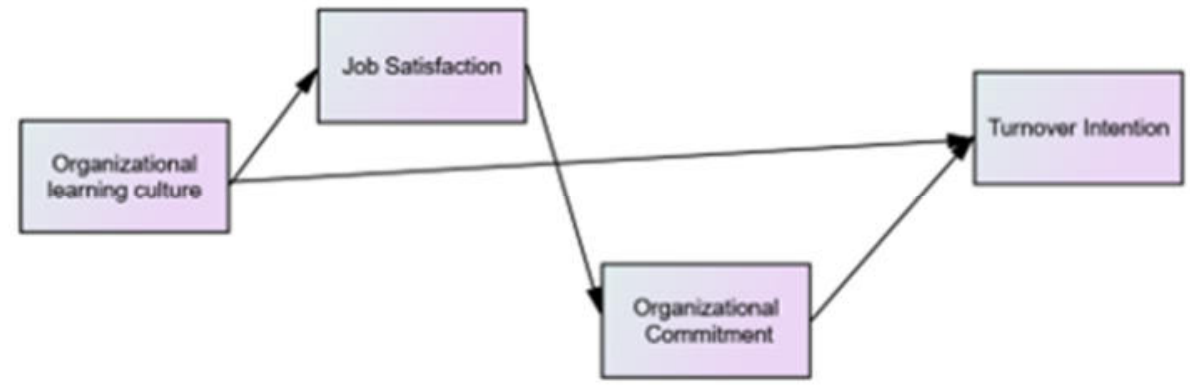

\section{Methodology:}

\subsection{Participants}

Data was collected by distributing a survey for some of the employees in the private sector in Saudi Arabia Riyadh city and there were some of the questions that related to the participant information the total number of the participant was 110 individual which consists of $38.2 \%$ female and $61.8 \%$ male, for the ages $10.9 \%$ their age is more than 40 years and 7.3 their age are more than 51 years which is shocked me I didn't accept this percentage with these ages, for the education degree the collected degrees from the participants was $65.5 \%$ they got a bachelor degree, 18.2 got a master degree, 10.9 diploma and 0.9 they got Ph.D., the job level of the participants was close to equally between two degrees beginner and supervisory, beginners level was $20.9 \%$ And the supervisory level was $26.4 \%$ but the managerial level was the hugest number of the participants by getting $52.7 \%$ in the survey. for the number of the experience that I have for the participant $46.4 \%$ of the participants, they have 5 years of the experience and below, $26.4 \%$ of the participants they have from 6 years till 10 years of experience and 27.2 of the participants they have more than 10 years of experience, For the retention of the participants in their companies, $68.2 \%$ of the participants spend 5 years and less in their companies, And $31.9 \%$ they spend more than five years in their companies but only $7.3 \%$ they spend more than 15 years in their companies, $50 \%$ of the participant they have 1000 employees and below in their companies, 32.7\% they got from 1001 till 10,000 employees in their companies and $17.3 \%$ they have more than 10,000 employees in their company.

\subsection{Data Collection}

Data were collected in this study by adopting measurement used in previous studies through using a questionnaire, it was consisting of 5 sections included demographic data section, the questionnaire was sherd via google forms and the measurements and the tools used in the questionnaire were the following:

The evaluation scale that we will use in the questionnaire DLOQ provided by Lien et al. (2006) consist of strongly disagree (1), disagree (2), neutral (3), agree (4), and strongly agree (5), the numbers front each element will be used to ask the participants to use when they fill the questionnaire.

The organizational learning culture measure was used by Ortenblad (2002) it's consisted of 21 items to measure the organizational learning culture, and the reliability of this variable reached .95 .

The job satisfaction measure was used by Spector (1985) and it's consisted of 10 items in the questionnaire to measure the job satisfaction variable, the reliability of this variable reached .83 .

for the organizational commitment variable was used by Allen and Meyer (1990) and it's consisted of 12 items in 
the questionnaire to measure the organizational commitment variable, the reliability of this variable reached .83 . and the last variable which is turnover intention was use by Bluedorn, (1982) consisted of 3 items and the reliability of this variable reached .71 .

The different number of each variable was used to measure the whole side of each variable and make sure the participants will understand each question even the question they could not be appropriate with the culture of Saudi Arabia were adjusted or deleted even to avoid the conflict if the answers in the survey to come up with the hopeless result in this research.

\subsection{Data Analysis}

The analysis of this study conducted through the statistical package of the social sciences (SPSS) and to have the regression of the variables, correlation of the variables, reliability of each variable as shown above in the data collection section and model fit summary and other statistical numbers in this study and the model of the variable of this study was drawn by the AMOS program and also was used for testing the quality of the model.

\section{Results}

4.1 Organizational Learning Culture and Job Satisfaction

A correlation test utilized Organizational learning culture and job satisfaction were correlated, the result of the correlation test was positive with $\mathrm{p}=<.001$.

\subsection{Organizational Learning Culture and Turnover Intention}

A correlation test utilized Organizational learning culture and Turnover Intention were correlated, the result of the correlation test was negative with $\mathrm{p}=<.001$.

\subsection{Job Satisfaction and Organizational Commitment}

A correlation test utilized Job Satisfaction and Organizational Commitment were correlated, the result of the correlation test was positive with $\mathrm{p}=<.001$.

\subsection{Organizational Commitment and Turnover Intention}

A correlation test utilized Organizational Commitment and Turnover Intention were correlated, the result of the correlation test was negative with $\mathrm{p}=<.001$.

Table 1 Summary of Correlations, Means, and Standard Deviation for Scores on the Organizational learning culture, Job Satisfaction, Organizational Commitment, and Turnover Intention.

\begin{tabular}{|c|c|c|c|c|c|}
\hline Variables & OLC & JS & $\mathrm{OC}$ & M & SD \\
\hline OLC & & & & 2.81 & .80 \\
\hline JS & $.884 * *$ & & & 3.03 & .79 \\
\hline $\mathrm{OC}$ & $.636^{* *}$ & $.711 * *$ & & 3.12 & .76 \\
\hline TI & $-.434 * *$ & $-.408 * *$ & $-.418^{* *}$ & 3.27 & 1.20 \\
\hline
\end{tabular}

OLC, Organizational learning culture; JS, Job Satisfaction; OC, Organizational commitment; TI, Turnover Intention. Correlation is significant at the 0.01 level (2-tailed).

4.5 Organizational Commitment, job satisfaction Organizational Commitment, and Turnover Intention

A linear analysis was done for the four variables that we have in this study and the variables are Organizational Commitment, job regression satisfaction Organizational Commitment and Turnover Intention the regression model was significant $\mathrm{F}(3.10)=10,12 \mathrm{p}=<.001, R^{2}=.22 R^{2}$ adjusted $=.201$ the regression coefficient $(\mathrm{B}=5.62$ this is the whole related to regression. 
Table 2 EE Dimension and Job Stress and Self-Efficacy

\begin{tabular}{lllll}
\hline Model & $B$ & $\beta$ & $t$ & $P$ \\
\hline Constant & 5.62 & & 12.41 & $<.001$ \\
OLC & -.490 & -.327 & -1.78 & .077 \\
Job Satisfaction & .093 & .061 & .306 & .760 \\
OC & -.398 & -.254 & -2.08 & .040 \\
\hline
\end{tabular}

OLC, Organizational learning culture; OC, Organizational commitment

4.6.1 Research Model Fit Using Path Analysis

Path analysis was utilized to check the study's hypotheses, which resulted in the default model being the perfect fit for best fit. Fit indices from the default model $\left[\chi^{2}=1.48 P=.928, \chi^{2} / \mathrm{df}=0.074 \mathrm{RMSEA}=.000, \mathrm{CFI}=1.000\right.$, $\mathrm{GFI}=.999$, $\mathrm{AGFI}=.997$, and $\mathrm{NFI}=.999]$.

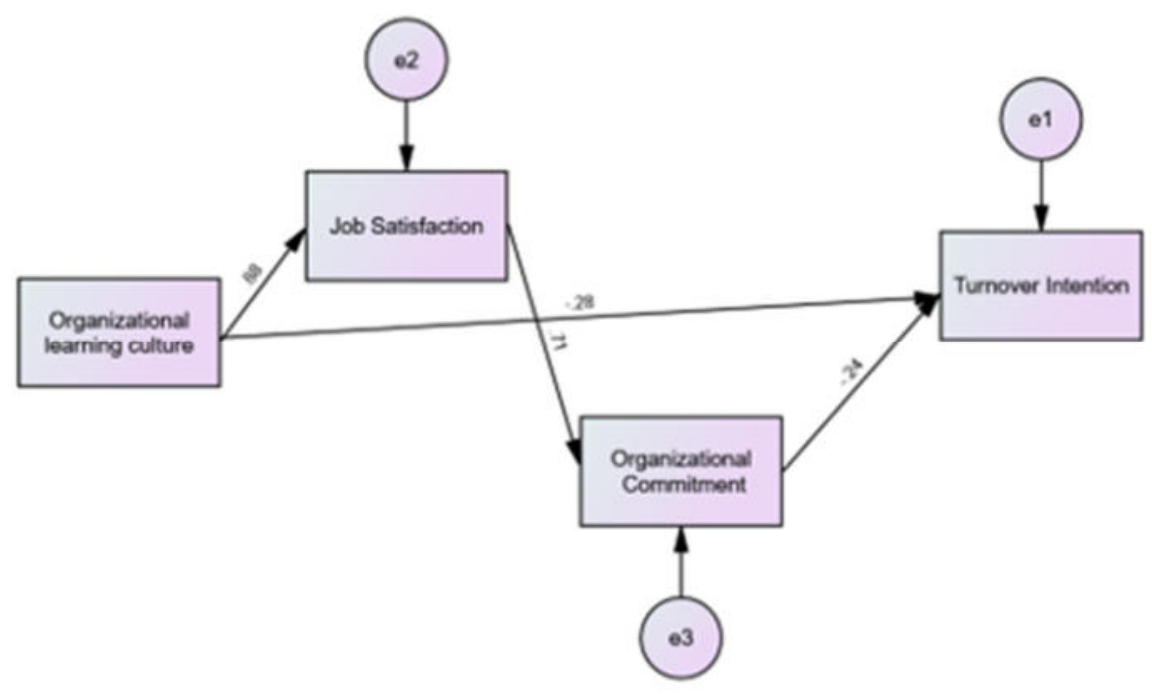

Table 3 The Fit Indices of Default Model

\begin{tabular}{lllllllll}
\hline Model & $\chi^{2}$ & df & $\chi^{2} / \mathrm{df}$ & RMSEA & CFI & GFI & AGFI & NFI \\
\hline Default Model & 1.48 & 2 & 0.074 & .000 & 1.000 & .999 & .997 & .999
\end{tabular}

RMSEA, Root Mean Square Error of Approximation; CFI, Comparative Fit Index;

GFI, Goodness-of-fit; AGFI: Adjusted goodness-of-fit; NFI, Normed-fit index

4.6.2 Path Coefficients in Default Model

Path coefficients as it showed in the below table, organizational learning culture had a positive direct effect with job satisfaction and same with organizational commitment but negative with turnover intention, for job satisfaction had a positive direct effect with all variables and organizational commitment had a positive direct effect with all variables except turnover intention. 
Table 4 Standardized Direct, Indirect, and Total Effects in the Default Model

\begin{tabular}{lccccccccc}
\hline \multirow{2}{*}{ Variables } & \multicolumn{3}{c}{ OLC } & \multicolumn{3}{c}{ JS } & \multicolumn{3}{c}{ OC } \\
\cline { 2 - 27 } & D.E. & I.E. & T.E. & D.E. & I.E. & T.E. & D.E. & I.E. & T.E. \\
\hline JS & .884 & .000 & .884 & .000 & .000 & .000 & .000 & .000 & .000 \\
OC & .000 & .628 & .628 & .711 & .000 & .711 & .000 & .000 & .000 \\
TI & -.282 & -.150 & -.432 & .000 & -.170 & -.170 & -.239 & .000 & -.239 \\
\hline
\end{tabular}

OLC, Organizational learning culture; JS, Job Satisfaction; OC, Organizational commitment; TI, Turnover Intention; D.E., Direct Effect; I. E., Indirect Effect; T. E., Total Effect

\subsection{Implications}

The current study's results have a number of implications for HRD theory and practice. The themes of organizational learning culture and work habits, as well as organizational learning culture in organizations environment, are highlighted in the theoretical implications. Practical consequences also illustrate the need for organizations practitioners to adopt an organizational learning culture, as well as the factors that can influence organizational learning culture and job behaviors.

For HRD Theory Implications, the conceptual structure identified by this study has two major theoretical implications. The first implication stems from the discovery that organizations with a strong learning culture have a direct impact on the work behaviors of organizations professionals. Although theoretical arguments about the value of learning organizations abound in the literature, research on the topic has yet to gain traction.

There is also a scarcity of empirical data on the impact of organizational learning culture on outcome variables such as work behaviors. Previous research has primarily focused on single behaviors like success, job satisfaction, organizational engagement, turnover intention, and innovation. The current research is important because organizations with an organizational learning culture will improve attitudes and operational outcomes.

In addition, three significant job behavioral variables were evaluated separately from the source of the organizational learning culture, and the mediated effects between organizational learning culture and three outcome variables were assessed in the current study. As a result, the current study not only discovered direct effects of organizational learning culture on job habits but also presented the indirect effects of organizational learning culture.

The second theoretical implication establishes a new research theme in which organizational learning culture variables are used to predict organizations professionals' job behaviors. Study at the organizations professional level is one of the study's strengths, while most previous research has focused on human resource management and organizations management. Previous HRD studies by Egan et al. (2004) and Lee-Kelley et al. (2007) looked at a sample of employees in the United States and the United Kingdom, respectively. These researchers discovered that organizational learning culture is a predictor of work satisfaction and the likelihood of turnover.

Implications for HRD Practice, as a result, this empirical study will expand the HRD research area, especially for organizations professionals in Asian cultures, and provide new insights into the impact of organizational learning culture on organizations professionals' success. organizations success is derived from organizational processes and governed by the organization's leadership, according to numerous studies (Jasswalla \& Sashittal, 1998; Keller, 2001; Thamhain, 2003).

This study backed up these claims because organizational learning culture has a significant impact on job performance, and strategic leadership was the most significant factor among the seven dimensions of organizational learning culture.

As a result, HRD practitioners will play an important role in creating a successful learning atmosphere by involving organizations management.

To create a learning organization, a number of techniques can be used, and these strategies include a variety of 
organizational variables, Environment, leadership, management, human resource strategies, company purpose, employee behavior, organizational culture, and organizational structure are all factors to consider (Senge, 1990).

One of the study's main focuses is on retaining highly trained organizations professionals. According to an analysis of the turnover rate of organizations professionals (Chang et al., 2008), organizations professionals have a high turnover rate because they are not granted enough autonomy or opportunity to match their intrinsic needs for learning and achievement. Furthermore, the majority of the study's participants were young and highly educated; the results show that these professionals are dissatisfied with their existing organizational learning cultures.

These low levels of satisfaction are linked to a high likelihood of leaving the business. HRD practitioners must have an appropriate learning organization to satisfy these young and highly trained professionals due to the unique characteristics of organizations professionals.

Organizational learning can be reinforced in a variety of ways, including by establishing an efficient learning group, communicating their vision with their staff, and so on. Organizations can encourage team learning by forming cross-functional work teams and peer discussion groups, as well as facilitating information acquisition and sharing (Marquardt, 1996; Watkins \& Marsick, 1993).

While learning organizations have been widely discussed in academic research studies, including meaning, explanation, and measurement, the readily available literature is more concerned with meanings and explanations than with measurement (Jamali \& Sidani, 2008).

Furthermore, the idea of a learning organization originated in western cultures, and it is still in its infancy and lacks empirical research, especially in global settings (Chang \& Lee, 2007; Lien et al., 2006), Nonetheless, this research has provided empirical and reliable evidence that HRD practitioners in Saudi Arabia can follow and implement their tasks.

The DLOQ (Marsick \& Watkins, 2003) is a valuable tool for measuring learning organization dimensions, and it can help HRD practitioners recognise their organization's strengths and weaknesses by reviewing their own learning organization implementation.

\section{Conclusion and discussion}

We found there is a positive relationship between the organizational learning culture and job satisfaction based on the previous studies shown below:

OLC has emerged as the preeminent training method for providing easy access to knowledge and a customized training experience, resulting in increased efficiency, productivity, and retention (Batalla- Busquets \& PachecoBernal, 2013; Brown \& Charlier, 2013; Navimipour, Rahmani, Navin, \& Hosseinzadeh, 2015; Yoo et al., 2015), Individual employee technology acceptance levels for e-learning systems and their effect on job satisfaction were examined by Yoo and Huang (2016) in the context of organizational learning, Exploring employee acceptance levels for e-learning programs, according to their results, will help cultivate an OLC.

Job satisfaction can be a key predictor of employee job attitudes that have been affected by an OLC or a knowledgesharing culture when considering the optimization of human resources and the retention of talent (Belias \& Koustelios, 2014, wong 2015, There have been no longitudinal research on the relationship between employee adoption of e-learning, expectations of an OLC, and work satisfaction. As a result, this analysis aimed to close the research gap by looking at the relationships between these three variables.

The research of Yoo and Huang (2016) helps to ensure that using e-learning systems can speed up the creation process, Egan et al. (2004) conducted a survey of IT industry workers in the United States and found that an OLC is a valid construct in predicting employee job satisfaction, HR professionals can improve employee psychological empowerment and work satisfaction while lowering attrition by strengthening an existing OLC (Chang \& Lee., 2007; Islam et al., 2014; Joo \& Park, 2010), When addressing the interaction between employee work satisfaction and the four underlying dimensions of e-learning system acceptance levels.

The current OLC must be considered. Understanding how the related variables of e-learning systems, OLC, and work satisfaction interact, is critical to provide HR researchers and practitioners with insights into how to build a workplace atmosphere that promotes effective learning and advancement in each profession. 
We found there is a negative relationship between the organizational learning culture and turnover intention based on the previous studies shown below:

Although organizational learning is among the most widespread and fastest-growing interventions in HRD practice (Cummings \& Worley, 2005), the context of organizational learning culture related to its interaction with turnover intention has not been explored extensively (Egan et al., 2004; Lee-Kelley et al., 2007), In the context of social exchange

theory, employees who receive sufficient and relevant training opportunities in organizations might be more reluctant to leave their organization (Shore, Tetrick, Lynch, \& Barksdale, 2006)

Thus, if employees perceive that they have more training opportunities, then it may result in diminishing their turnover intention (Chow, Haddad, \& Singh, 2007; Dysvik \& Kuvaas, 2008; Hemdi \& Nasurdin, 2006; Pfeffer \& Sutton, 2006). Similarly, Lankau and Scandura (2002) reported that job learning is negatively associated with turnover intention. Karatepe, Yavas, and Babakus (2007) suggested that job resources, including supervisory support, training, empowerment, and rewards, increase employees' job satisfaction and affective commitment and reduce their turnover intention. Pare and Tremblay (2007) indicated that competence

development and information sharing have a negative effect on turnover intention. While there is limited empirical evidence to support a relationship between organizational learning culture and turnover intention, the research that has been done supports this connection.

Based on Gouillart and Kelly (1995), and organizational culture that encourages employees' self-development may reduce individuals' desire to seek employment elsewhere if they are acquiring new skills and competencies that allow them to increase their self-efficacy.

Egan et al. (2004). demonstrated that a learning culture impacted job satisfaction; in addition, a learning culture was mediated by job satisfaction, with a negative effect on turnover intention. Lee-Kelley et al. (2007) conducted a study exploring learning organizations and the retention of knowledge workers in the private industry.

The researchers applied Senge's five learning organization disciplines to explore the relationship between job satisfaction and turnover intention. They concluded that shared vision, which is one of the learning disciplines, has a negative relationship to turnover intention because knowledge workers were strongly influenced by a shared vision and showed decreased turnover intention.

We found there is a positive relationship between job satisfaction and organizational commitment based on the previous studies that shown below:

Organizational commitment and job satisfaction are considered distinct constructs. Job satisfaction is an emotional state that reflects an effective response to one's job and work environment (Gregson, 1987; Lock, 1976; Porter et al., 1974), Organizational commitment, on the other hand, puts a greater focus on a global response (emotional or non-emotional) to the whole organization (Lance, 1991; Porter et al., 1974). As a result, everyday events have less of an effect on organizational loyalty, and it develops more consistency over time than work satisfaction (Mowday, Steers, \& Porter, 1979; Sagie, 1998), Even though there is a general agreement that there is a clear positive relationship between work satisfaction and organizational commitment, there is a debate about the

causal order of these two variables. Strasser and Bateman (1984), argued that organizational loyalty is a predictor of job satisfaction, implying that when workers have a deep commitment to their company, their job satisfaction will increase. Job satisfaction has been linked to organizational commitment in many other studies (Bluedorn, 1982a; Williams \& Hazer, 1986), A third viewpoint regards the relationship as mutual (Mathieu \& Zajac, 1990; Meyer, Staneley, Herscovitch, \& Topolnytsky, 2002).

Much research tends to show that job satisfaction is affected by a variety of other factors that have a positive effect on organizational commitment. Training and education (Griffeth et al., 2000; Yu \& Egri, 2005), and ethical climate (Cullen, Parboteeah, \& Victor, 2002; Schwepker, 2001), a supportive and innovative culture (Lok \& Crawford, 2001), role stressors (Griffeth et al., 2000; Yu \& Egri, 2005), and role stressors (Griffeth et al., 2000; Yu \& Egri, 2005 (Igbaria \& Guimaraes, 1993; Johnston, Parasuraman,

Futrell, \& Black, 1990), and professional growth (Igbaria \& Greenhaus, 1992). As result, this study takes this stance because the employees enjoy autonomy and versatility, and when they are happy in their employment, they are more likely to identify with and participate in their organizations (Goswami et al., 2007), As a result, they are more likely to have "a firm belief in and appreciation of the organization's goals and principles" (Mowday et al., 
1979, p. 226)

Overall success in an academic institute is determined by a teacher's actions and attitudes, which should be nurtured in such a way that the teacher's job satisfaction and dedication are increased (Bashir and Gani, 2019). Positive job satisfaction, according to Grace and Khalsa (2003), will improve a teacher's organizational commitment, Employees who work in a positive university setting are more likely to be satisfied with their jobs (Anari, 2012), which increases organizational commitment and increases university productivity (Sabri et al., 2011; Malik et al., 2010).

We found there is a negative relationship between the organizational commitment and turnover intention based on the previous studies that shown below:

According to Barak et al., work satisfaction, organizational commitment, technical commitment, and burnout are the best predictors of turnover intention (2001). Indeed, several research on the motivation to leave have found that work satisfaction and organizational commitment are both important factors (Carayon, Schoepke, Hoonakker, Haims, \& Brunette, 2006).H4: there is a significant negative relationship between organizational commitment and turnover intention, "The presence of organizational commitment in the causal mechanism leading to turnover intention" is strongly supported by the clear relationships between satisfaction, commitment, and turnover intention (Bluedorn, 1982a, p. 88).

Many studies of organizational commitment and turnover intention have been conducted in the past. Mathieu and Zajac (1990) accepted Nowadays et al.'s (1982)'s prediction that organizational commitment has a negative relationship with turnover intention in a meta-analysis of 200 commitment studies.

their research also found that employees who are dedicated to their employers are more likely to stay with them. Similarly, Tett and Meyer (1993) discovered that organizational commitment was a predictor of turnover intention in a meta-analysis of 155 studies with 178 independent samples. Using a longitudinal design, Johnston et al. (1990) supported these results.

As previously mentioned, organizational commitment is made up of three elements: affective, continuous, and normative (Meyer \& Allen, 1991). While the majority of studies on affective commitment have found that the strongest and most stable relationship with turnover intention is with affective commitment (Iverson \& Buttigieg, 1999; Meyer \& Allen, 1997; Vandenberghe \& Tremblay, 2008; Wasti, 2003).

researchers have found a significantly negative relationship between continuance commitment and turnover intention (e.g., Chen, Hui, \& Sego, 1998; Jaros, Jermier, Koehler, \& Sincich, 1993; Meyer et al., 2002; Udo, Guimaraes, \& Igbaria, 1997), Pare and Tremblay (2007) investigated the effect of continuity commitment on turnover intention and discovered that employees are likely to remain with their company not only because of emotional connection, but also because of financial incentives, but also because of the expense of quitting.

As a result, it has been discovered that continuance commitments processed as a perceived expense correlate more strongly than affective and normative commitments (Dunham, Grube, \& Castaneda, 1994; Meyer, Allen, \& Gellatly, 1990; Wasti, 2003), These findings are supported by research findings in the literature for organizations professionals (Chang \& Choi, 2007; Iverson, Mueller, \& Price, 2004).

\section{References}

Relationship between Employee Commitment, Job Satisfaction, Career Satisfaction, Turnover Intention, and Organizational Commitment amongst Professional Engineers Employees 2020 by MORRIS TUNDE OGUNLEYE.

Employee turnover intentions and job performance from a planned change: the effects of an organizational learning culture and job satisfaction 2020 by Lin Chun yu.

Will They Stay or Leave? The interplay of Organizational Learning Culture and Workplace Mindfulness on Job Satisfaction and Turnover Intentions 2021 By Lin Chun yu, hang Chung kai, li Hung Xin, Chang Tai Wei, Hsu Yu chia.

Dimensions of HR differentiation: The effect on job satisfaction, affective commitment, and turnover intentions 2019 by Przemyslaw. 
2020 Fourth International Conference on I-SMAC (IoT in Social, Mobile, Analytics, and Cloud) (I-SMAC) ISMAC (IoT in Social, Mobile, Analytics, and Cloud) (I-SMAC), 2020 Fourth International Conference on. :508513 Oct 2020.

Exploring Workplace Bullying and Turnover Intention among Registered Nurses in Tertiary Hospitals, Lahore, Pakistan 2021 by Mishal Liaqat1, Iram Liaqat2, Rizwan Liaqat Awan3, Rabia Bibi4.

Social capital and resilience make an employee cooperate for coronavirus measures and lower his/her turnover intention 2020 by Kokubun, Keisuke, Ino, Yoshiaki Ishimura, Kazuyoshi.

Occupational Health and Safety and Turnover Intention in the Ghanaian Power Industry: The Mediating Effect of Organizational Commitment 2019 by Suxia Liu, Emmanuel Gyabeng , Gilbert Joshua Atteh Sewu, Nana Kwame Nkrumah , and Bright Dartey.

Organizational Commitment for Knowledge Workers: The Roles of Perceived Organizational Learning Culture, Leader-Member Exchange Quality, and Turnover Intention 2019 by Baek-Kyoo.

Demographic factors, compensation, job satisfaction and organizational commitment in private university: an analysis using SEM 2020 by Mohammed Ashraf.

Enhancing Employee Job satisfaction via E-learning: The Mediating Role of an Organizational Learning Culture 2019 by Chun-Yu Lina, Chung-Kai Huong, and Hao Zhangc. 